\title{
Review of Psychological Factors That Cause the Game to Charge Money
}

\author{
Jingxin Wang ${ }^{1, *}$ \\ ${ }^{1}$ Chongqing Nankai secondary school, Chongqing, China. \\ ${ }^{*}$ Corresponding author. Email: guanghua.ren@gecacademy.cn
}

\begin{abstract}
Nowadays, with the gradual popularization of the Internet, the influence of game top-up is gradually expanding. There are a few stories in the news about game charging, and most of them are about family conflicts or irreparable economic losses caused by excessive charging. This research will investigate the subjective reasons why gamers charge money into games. This research uses three theories through all paragraphs, and the whole paper adopts the literature review method. First, the Agent system allows players to introduce themselves to the characters in the game to achieve emotional resonance with the character, which provides the basis for analysis. Second, Maslow's hierarchy of needs tells the process that people need to go through from basic needs to self-actualization. Through this theory, we can figure out the subjective reasons why people put money into games. Finally, Erikson's Stages of Personality development describes people's different needs for life at different ages. By combining this theory with data, the conclusion can be further proved. These two theories support the conclusion. This research turns out that people spend money on games because they want to feel more like they belong. The results provide a possible solution for people to prevent overcharging.
\end{abstract}

Keywords: Game, Agent system, Maslow's hierarchy of needs, Erikson's Stages of Personality development.

\section{INTRODUCTION}

There has been a lot of news in recent years about excessive money pouring into games. For example, there was a 14-year-old girl who spent 60,000 yuan on a game and decided to make up for her mistake by committing suicide after she realized it was wrong. A primary school student, two months crazy, rushed toward the game 160 thousand yuan, just for the experience of big money in the game when the feeling. Another student poured half a million yuan into the game, prompting people to lament that the game was poison[1, 2, 3]. Both of these stories are about minors who are addicted to the game, and they're pouring huge amounts of money into the game. One ends it all with suicide, the other with a parent crying for their money back. These cases all show the serious consequences caused by people's addiction to money in games and their inability to control themselves. Because the children are addicted to the game top-up, the family economy is in trouble, and the parent-child relationship is poor. In ordinary life, people can notice that many friends are spending money on games, and there have been stories in the news of gamers taking out loans to fund their games or getting scammed for doing so. A question came out, why charging for games was so appealing. Since everyone can find that ancient mobile games require a lot of money, the typical Moon Light in ancient mobile games is a good sample to do the research object. Ancient Jianghu game is a kind of game that will create An ancient environment and atmosphere. The player also manages a lot of stories, and there's a lot of love and hate in those stories. The player has to learn the story bit by bit, to solve the misunderstandings and puzzles, and in these stories, there is always many fight and death. In addition, there are other ways to play the game. We can buy fancy clothes, sell resources to improve our strength, build our gang, make friends, interact with NPCs and find love.

Most of the existing research on spending money on games has focused on how marketers can entice players to pay, such as reward removal and competitive stimulation[4]. Few studies from the player's point of view have only shown that players are the same as gamblers. This causes us to think about that if there were 
other motivations for players to pour money into the game besides the gambler's mind.

The goal of this paper is to explore the psychology of games, and since I am also addicted to games, and hope the result of this research into the psychology of games will help me stay away from games. Because in evolution psychology, only things that are useful to humans are left behind, according to this theory, games should be useful to humans as well [5]. And if it can prove that playing games are needed, it can refute some parents who blame games for their children's poor learning[6]. If the research can figure out why games are psychologically addictive, parents who blame their children for playing games use the wrong way to stop children from playing games, and people can understand persons who are addicted to playing games and look for better solutions from them. I have other reasons for this, as children have wasted a lot of money on my gaming addiction. Most parents chose to blame me and confiscate the phone. But this didn't stop children from loving the game. Children will control themselves not to add money to the game, but their hearts are painful. If we can find out the underlying reasons why people want to spend money, we can make the process of quitting gaming a little easier.

\section{METHOD}

The research method of this paper is a literature review. Literature review refers to reasoning and proving one's point of view by citing and analyzing the viewpoints proposed by predecessors and some existing facts. This paper is based on the theory of Evolution's pedagogy, Maslow's Hierarchy of Needs, and Erikson's Stages of Personality Development theory are used as the support and credible data and news facts on the Internet. These three theories are chosen as the basis for this article because they explain what people want from games.

\section{EVOLUTION’ S PEDAGOGY}

In 2001, Professor Francis Steen and Professor Stephanie Owens co-wrote Evolution's Pedagogy: An Adaptationist Model of Pretense and Entertainment[7]. This paper proposes that Entertainment is a simulated state. When the animals are entertained, the surroundings provide basic safety conditions, and then the participating animals bring themselves into the characters in the scene. A typical example in this paper is that small animals in a chase game will put themselves in the role of predator or prey and perform certain role-specific behaviors, such as predators being aggressive and biting their prey. This example suggests that entertainment may have emerged in the first place to help us learn survival skills. This article also points out that entertainment encourages people to play games may be that people can explore the possibility space of themselves and discover many skills that they have not discovered before. The surprise of discovering new skills will be a major factor that urges people to continue playing games. In Japanese Anime Heroines as Role Models for U.S. Youth, In the article about Wishful Identification, Parasocial Interaction, and Intercultural Entertainment Effects, the author also mentioned why people have empathy for the characters in the movies[8]. In this article, the author proposes that people like a movie character because the character is similar to the audiences. We can find that there are always difficulties in the movie, and then it will show how the protagonist overcomes the difficulties and succeeds in getting what he wants. This is the same as real life. People will also encounter various difficulties, but often not so easy to solve, not so easy to succeed. But the characters in the film give audiences an example of success and inspire admiration. At this time, the media will create an opportunity to meet with the cosplayer, and people will pay money to buy tickets to meet the cosplayer because of their admiration. The same is true of the rice circle culture. Setting up a celebrity who breaks through layers of difficulties to become famous is often more successful and safer than setting up a celebrity who has had a smooth ride. After all, difficulties are the norm in life. Of course, in my research, I only used the theory that people put themselves into characters when they are having fun. The phenomenon happens in animals' life can also be reflected in people's entertainment life. In chase play, children playing the role of hider and pursuer behave differently depending on their role. Furthermore, when we watch TV shows, people with low tears will cry along with the main actors and actresses. This is because when people watch TV, they bring their own emotions into the characters' emotions. Hence, it can be seen that as long as it is entertainment, this phenomenon will be produced When we play games, we draw ourselves into the characters in the game. So we spend money to buy clothes and equipment in the game is the same as buying clothes and learning knowledge in real life. In reality, good clothes and rich knowledge can attract more people's attention. Similarly, buying good-looking clothes and strong equipment can attract more people to make friends in the game. These environments, identical to real-life Settings, provide the player with a basic condition to immerse themselves in the game character. After the player has successfully brought themselves into the game character, when they play the game, the story in the game seems to be a real experience in his eyes, and his emotions will change with the changes of the character's situation in the game. People can spend money to have a better experience, so the sense of bringing it into is a reason that drives people to spend money on games.

\section{MASLOW'S HIERARCHY OF NEEDS}

In 1943, Maslow, a humanist psychologist, proposed Maslow's hierarchy of needs theory[6]. In this theory, Maslow pointed out that human needs can be divided into five categories -- Physiological, Safety, Love and 
Belonging, Esteem, and self-actualization. After satisfying basic physiological and security needs, Maslow pointed out that people would begin to pursue spiritual satisfaction, such as searching for belonging and love. After satisfying belonging and love, people would seek self-esteem. After satisfying self-esteem, they would pursue self-realization. An article on a website called Overwell Mind says there is a link between game addiction and emotional dependence on games and difficulties with social interaction in daily life. And social and emotional dependence belongs to love and belonging. Therefore, we can speculate that a person who wants to make friends in real life but is not good at social interaction is more likely to start playing games. After developing emotional dependence on games, the player will discover that more people will be willing to make friends by charging money to increase his strength. Hence, this kind of person will start pumping money into the game. Of course, if people feel lonely and bored alone at home, they might want to play games. Because games can be a great way to socialize when they feel lonely. Evolutionary psychology also explains why people like to play games[9]. Darwin put forward the theory of evolution. This theory advocates the idea of survival of the fittest, and all that remains is useful. When applied to people, it means that human organs and living habits are useful. When applied to games, games must be beneficial to human beings if they are left behind. The game's benefit is that it can bring love and belonging to people, which fulfill people' s needs and are good for them, so games can survive and be popular. Behavioral psychology can also explain why people keep pouring money into games[9]. Behaviorism is Pavlov's idea. The idea is that human behavior and habits can be cultivated by linking unconditioned and conditioned reflexes. The classic example is Pavlov's dog. In this experiment, Pavlov fed dogs while ringing a bell. After doing this over a long period, dogs salivate even when they are not given food and only ring a bell. And what researchers going to use is reinforcers theory in behaviorism. Skinner raised and tested this theory with pigeons[9]. Skinner in feeding eight pigeons in a cage, to enhance the motivation of looking for food, for a few days before the test let pigeons hungry, and then use food distributor in the cage to feed. The dispenser is set to every 5 minutes to distribute food, that is to say, regardless of what pigeons did every five minutes will receive a prize. Six of the eight pigeons responded significantly: one dove circled the cage repeatedly; Another repeatedly banged his head into a corner of the cage; The third exhibited an upward-lifting response as if placing its head under an invisible bar and repeatedly lifting it; The heads and bodies of two pigeons showed a sort of swaying motion; Another pigeon developed an incomplete conditional response to a peck or tap as if the pigeons thought they would get food if they repeated the action. We're just like these pigeons when we play games. When we add money to the game, we get in-game rewards. And we take it for granted that if we put money in, we'll get the same return every time. But later in the game, the reward for charging the same amount of money decreases. To get the same reward as before, the player will continue to increase the amount of money, resulting in tragedy.

\section{ERIKSON'S STAGES OF PERSONALITY DEVELOPMENT}

A psychodynamic school of thought, Erikson put forward Erikson's Stages of Personality Development[9]. In this theory, Erikson divides the development of human beings into eight stages, which are Infancy (1st year), Toddler (2nd year), Preschooler (3-5years), Elementary (6year-puberty), Adolescence (teens into 20's), Young adults (20 'to early '40s), Middle adults (40' -60 '), Late adults (late 60 's). Different ages determine different characteristics of people. In the Infancy (1st year), people are looking for security. In the Toddler(2nd year), people will seek a sense of their existence. In the preschooler (3-5 years), people will learn to take the initiative. In Elementary (6year-puberty), people learn the pleasure of applying themselves to tasks. In the Adolescence (teens into '20s), people work at defining a sense of self. In Young adults (20 'to y '40s), people struggle to form a close relationship and to gain the capacity for intimate love. In the Middle adults (40' -60'), people discover a sense of contributing to the world. In the Late adults (late 60 's), people reflecting on their life. This theory gives us different psychological needs at different ages. Because it covers all a person's needs from birth to death, it is used in many different disciplines. For example, parenting experts will use this theory to recommend books suitable for children, and sales experts will use this theory to analyze how to sell products to customers. In addition to this theory, Piaget's Stages of Cognitive Development has Cognitive posed a similar theory about how people change with age in developmental psychology[6]. In this theory, Piaget put forward that children around two years old are in Sensorimotor, there is no concept of object permanence, and stranger anxiety will occur. Children between the ages of two and four are in the Preoperational stage. When they become self-centered and begin to imitate and learn the behaviour and language of behavior, children aged 7 to 11 are in the Concrete operational stage when they cannot understand the conservation of mass and arithmetic. Children from age twelve to adolescence are in the Formal operational stage, when they acquire abstract thinking and focus on moral issues. However, this theory has not been widely used because of the following experimental results opposite it. Back to the theory of Erikson's Stages of Personality Development. A data copy from Statistait shows that Statistat ween the ages of 20 and 50 account for about 70 percent of all gamers[9]. According to Erikson's Stages of Personality development, people aged between 21 and early40 have 
the same characteristics of intimacy and loneliness. And the 40's-60's would get a characteristic of generativity and forces. We will find that both characteristics determined by the two ages have something to do with people's love and belonging.

\section{CONCLUSION}

Going back to the original question, why do so many gamers put money into a game? Agent System, Maslow's Hierarchy of Needs theory and Erikson's Stages of Personality Development are used in the analysis. Agent system refers to people who bring themselves into a game or TV show to create empathy. This theory allows us to connect real life and game life, because when we play a game, we bring ourselves into the game. Maslow's hierarchy of needs describes the gradual process from basic needs to self-actualization. This theory makes a preliminary conjecture about why people play games -people play games to find a sense of belonging. Erikson's Stages of Personality Development gives an idea of what people need at different ages. This theory further confirms that people play games to find a sense of belonging. Through analysis, the result is that people play games because games provide a sense of belonging. Because people need to belong, games capture that need. The game provides a series of Settings such as making friends and falling in love that can enhance people's sense of belonging and require players to pay money for these Settings before enjoying them thoroughly. This makes gamers willing to pay into the game to achieve belonging.

The research could help people who need to stop being addicted to the Internet or to gaming. Reducing their desire to find that feeling in games by increasing their sense of belonging, in reality, is a much gentler way to go than forcing a withdrawal. Of course, this approach can also avoid a lot of family conflicts caused by the game. The results should also serve as a warning to parents that children are not born addicted to games. It may be the environment or the family that causes this, so do not blindly blame the child. Overall, the most important role of this experiment is to find out the subjective reasons why people like to spend money on games, which can provide a possible solution to help people who can't control spending their money on games.

\section{REFERENCES}

[1] CCTV International Network Limited center(2020). "14-year-old girl charged to" money burning "games: She charged 60,000 Yuan a Month and Committed Suicide ", [Online]Retieved August 27, 2021. from https://baijiahao.baidu.com/s?id=16688923265048 $68781 \& w f r=$ spider $\&$ for $=$ pc

[2] Shanxi Broadcasting and Television Station(2019). Minors waterfront waterfront to games, poured
500,000 yuan into the game, and the game became" poison ", [Online]Retieved August 24, 2021. from https://baijiahao.baidu.com/s?id=163729510250224 $6916 \& w f r=$ spider $\&$ for $=p c$

[3] Span 3B fat House (2019), Primary school game addiction, two months crazy recharge $16 \mathrm{~W}$, just like when the "big guy" feeling, [Online]Retieved August 15, 2021. from https://zhuanlan.zhihu.com/p/75240406.

[4] Tyler Amano-Smerlin. (2021). Pay to Play: The Ethics of Video Game Economics. [Online]Retieved August 20, 2021, from https://vce.usc.edu/volume5-issue-1/pay-to-play-the-ethics-of-video-gameeconomics/

[5] Stanford Encyclopedia of philosophy (2008). Evolutionary psychology. [Online]Retieved August 26, 2021, from https://plato.stanford.edu/entries/evolutionarypsychology/

[6] Allyson J. Weswley, Ed.D. and Robert McEntarffer Ph.D.(2020). AP psychology, WESELEY AND MCENTARFFER Press.

[7] Francis Steen and Professor Stephanie Owens(2001). Cognitive and culture. Evolution's Pedagogy: An Adaptationist Model of Pretense and Entertainment, 289-321.

[8] Srividya Ramasubramanian \& Sarah Kornfield (2012), Japanese Anime Heroines as Role Models for U.S. Youth: Wishful Identification, Parasocial Interaction, and Intercultural Entertainment Effects, Journal of International and Intercultural Communication, 189-207, DOI: 10.1080/17513057.2012.679291.

[9] David G. Myers and C. Nathan DeWall(2010). Myers , Psychology for the AP course, Worth Publishers Press.

[10] J. Clement (2021), Global gamer share worldwide in 2017 , by age and gender. [online] Retieved July 24, 2021. from https://www.statista.com/statistics/722259/worldgamers-by-age-and-gender/ 